\title{
Development of a GIS based screening tool for evaluating stormwater harvesting sites in urban areas
}

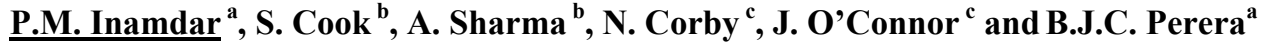 \\ ${ }^{a}$ Victoria University, P.O. Box 14428, Melbourne, Victoria 8001 \\ ${ }^{b}$ CSIRO, Highett, Land and Water, Melbourne, Victoria \\ ${ }^{c}$ City West Water, Melbourne, Victoria \\ Email: prasadmohanrao.inamdar@live.vu.edu.au
}

The recent drought in Australia, together with concerns about climate change and growing urban demand for water have highlighted the need of managing water resources in a more sustainable way. Water supply restrictions have been used by respective State Governments in major Australian cities to cope up with dwindling water resources. Since the last decade, alternative, non-traditional water resources have been seen as an increasingly attractive means to supply non-potable urban water demands. Among several alternative water resources, stormwater harvesting and reuse has emerged as a viable form of sustainable water management, as it not only offers a potential alternative water supply for non-drinking water uses and thus improving the security of water supply, but also provides a means to reduce stormwater pollution in waterways.

In the urban context, the selection of suitable stormwater harvesting sites is of prime importance for water managers, and must be established in order to develop the detailed engineering designs. In this regard, Geographic Information Systems (GIS) can be utilized as effective tools to analyze various spatial datasets. The current literature focuses on applying GIS to identifying suitable stormwater harvesting locations in rural catchments. However, the application of GIS has been very limited in existing urban areas for identifying suitable sites for stormwater harvesting. To address this knowledge gap, the present research was focused on developing a GIS screening tool for identifying potential stormwater harvesting locations in existing urban areas, using pre defined suitability criteria. The methodology was then applied to an existing urban area to identify suitable stormwater harvesting sites.

A portion of the Melbourne City Council (MCC) within the service area of water retailer, City West Water (CWW) was considered as the case study. CWW is one of the three retail water companies in the Melbourne metropolitan area, Australia, providing water, sewage, trade waste and recycled water services to its residential and non-residential customers. The key criteria considered for developing the screening tool were urban runoff and water demand. These criteria were evaluated with respect to 'accumulated catchments', which was a concept introduced in this study. The accumulated catchments referred to here were the aggregated upstream catchments increasing in drainage area from upstream to downstream of the catchment. Spatial maps were generated for each of these criteria. This procedure involved extensive data collection from CWW, different Australian Government authorities and research institutions.

The rational method was used to estimate potential runoff, which involved integration of a pervious-impervious area map, a runoff coefficient map and an interpolated rainfall map. The runoff analysis was done using the annual average values of rainfall for the drought period of 1997-2009. Water demands considered included irrigation demands from parks, ovals, and council reserves, which were represented in GIS as demand volume per park landuse area. Demand analysis was undertaken using water consumption values of the parks for year of 2010. Annual scale chosen was deemed suitable for this preliminary screening process.

The accumulated catchment layer was generated from the Digital Elevation Model (DEM) of 10m. The runoff and demand layers were overlayed with accumulated catchments to obtain the ratios of available runoff to required demands from each of the accumulated catchments. The drainage outlets of the accumulated catchments were thought as potential stormwater harvesting sites. Thus, sites with high ratios of supply to demand indicated the high suitability of a given accumulated catchment for stormwater harvesting.

The drainage outlets of high ratio catchments were selected, ranked and termed as suitable stormwater harvesting sites. Thus, the GIS screening tool methodology has provided a rational approach in identifying potential sites for stormwater harvesting in existing urban areas, which will aid water authorities such as CWW in their infrastructure planning and decision making. Once the suitable sites are identified from the GIS based screening tool, detail conceptual designs will be developed for these identified sites. These sites will be evaluated the with respect to social, environmental and economic criteria to select the most suitable sites and designs, as part of future research.

Keywords: Stormwater Harvesting, Urban Area, GIS, Suitability Analysis, Accumulating Catchments 


\section{INTRODUCTION}

Among several alternative water resources available for reuse, stormwater is the most preferred by the general public, especially when compared to recycled wastewater (Mitchell et al. 2002; Fletcher et al. 2008). Stormwater harvesting and reuse is a widely used practice which deals with collection, storage, treatment and distribution through various engineering approaches (Hatt et al. 2006; Mitchell et al. 2007; Goonrey et al. 2009). In the Australian milieu, rainwater harvesting is termed as the collection of rainwater from rooftops before it hits ground. If not harvested directly from rooftops, rainwater becomes part of stormwater.

In the urban environment, the selection of suitable stormwater harvesting sites is of prime importance for water infrastructure planners. In this regard, Geographic Information System (GIS) has been recommended as a decision making tool to facilitate the identification of potential stormwater harvesting sites during the decisionmaking process (Mbilinyi et al. 2005). GIS can serve as screening tools for preliminary site selection as they have a unique capability for spatial analysis of multi-source datasets with their integration (Malczewski 2004).

There is extensive literature available on the use of GIS for the assessment of site suitability in rural areas in terms of stormwater harvesting across the world. In India, potential sites for water harvesting structures were identified using International Mission for Sustainability Developments (IMSD) guidelines within a GIS environment (Kumar et al. 2008; Singh et al. 2009). In South Africa, GIS based decision support systems have been developed for identifying suitable locations for water harvesting in numerous studies (De Winnaar et al. 2007; Mbilinyi et al. 2007; Kahinda et al. 2008).

Determining criteria to support a strategy for identifying suitable runoff harvesting sites requires a biophysical approach, where information based on physically derived catchment characteristics is used for understanding the catchment's hydrological response (De Winnaar et al. 2007). Various studies (El-Awar et al. 2000; Mbilinyi et al. 2005; Kahinda et al. 2008) considered several physical criteria which deemed to be suitable for stormwater harvesting which included rainfall conditions, runoff, topography, drainage conditions, soil type, distance to storage, etc.

These criteria are more relevant in rural areas, where there are less spatial constraints for water storages. However, in an urban context, in addition to the issues on less storage space and existing drainage network, the social, institutional and economic factors often put further constraints on locating suitable stormwater harvesting sites. From an urban Australian perspective, the only GIS work found in the literature was the work of Shipton and Somenahalli (2010), where GIS were applied in identifying suitable stormwater harvesting locations in the Central Business District of Adelaide. However, the Shipton and Somenahalli study was limited in identifying stormwater harvesting sites only based on suitable land use and drainage pattern, and demands for stormwater were not accounted.

The literature review conducted in this study found that GIS has rarely been applied to existing urban areas in identifying suitable sites for stormwater harvesting. To address this knowledge gap, the present study was aimed at developing a GIS screening tool methodology for identifying stormwater harvesting sites in existing urban areas. The methodology was applied to a portion of the Melbourne City Council region (MCC) in City West Water (CWW) servicing area.

\section{STUDY AREA}

CWW is one of the three water retail authorities in the Melbourne metropolitan area. It supplies drinking water, sewerage, trade-waste and recycled water services to customers in Melbourne's central business district, inner and western suburbs. CWW's servicing area includes 9 different city councils with different socio-economic status. The present study focuses on a portion of Melbourne City Council (MCC) of area $26 \mathrm{~km}^{2}$ within CWW's service area of $640 \mathrm{~km}^{2}$ (Figure 1). The topography of the municipality is mostly flat with the $70 \%$ of its land having a slope less than $5 \%$. The area is highly urbanised, including the Central Business District of Melbourne (CBD) which comprises predominantly commercial land use and other mixed land uses such as public park, reserves, residential and industrial. The non-residential water demand for the council in year 2010 was estimated as $11 \mathrm{GL}$. This nonresidential demand is mainly commercial water use which

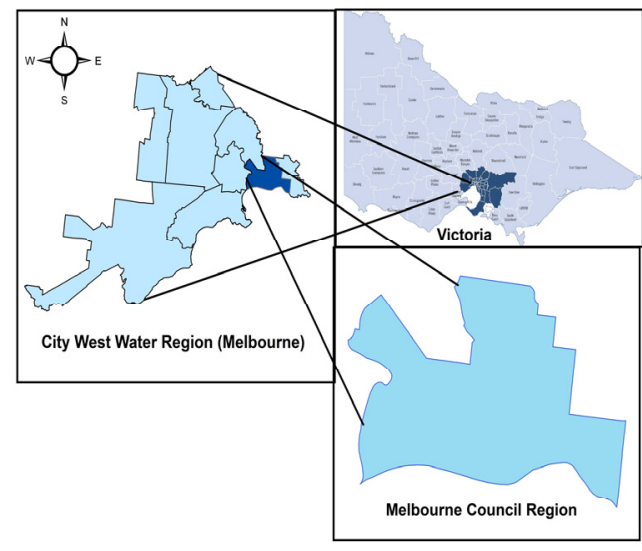

Figure 1. Melbourne City Council in City West water Area 
constitutes $65 \%$ of the total non-residential demand. The next highest non-residential demand results from the irrigation of parks and open spaces accounting for $12 \%$ of the non-residential demand in the area.

\section{METHODOLOGY}

The methodology for developing the GIS screening tool in the study consists of three broad steps: (a) Criteria selection for stormwater harvesting suitability, (b) Data acquisition and processing to create spatial maps for identified criteria, and c) Estimation of indices of suitability and ranking of suitable stormwater harvesting sites. Figure 2 shows in brief the steps used in the methodology.

In step (a), runoff and demand were considered as main suitability criteria as they are the primary drivers for any stormwater harvesting scheme. The runoff criteria consider runoff generated from impervious and pervious areas within the study region. The water demand addressed here are irrigation demands for the parks and open spaces. Scope of the study, however, can be extended to supply stormwater to meet various non-residential demands, and residential demands with adequate treatment.

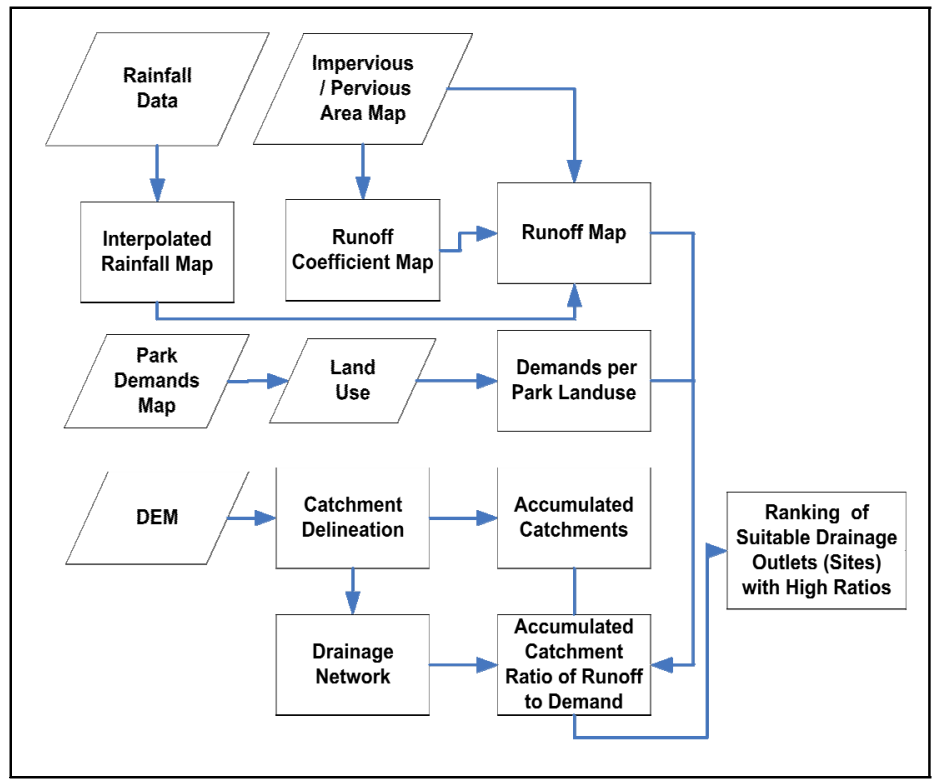

Figure 2. Flowchart of Methodology The stormwater harvesting catchments were considered as the 'accumulating catchments' with their runoff and demand.

The accumulated catchments here are defined as aggregated or individual upstream catchments, which increase in size from upstream to downstream of the catchment. The accumulated catchment concept is explained in Figure 3. Sub-catchment $a$ and $b$ are upstream catchments which drain at outlet-1 and outlet-2 respectively. The sub-catchment $c$ here is an accumulated catchment, which encompasses subcatchment $a$ and $b$ with an additional drainage area; drains at outlet-3. The sub-catchment $\mathrm{d}$ which is an upstream catchment; drains at outlet-4. The catchment- $c$ and catchment- $d$ aggregate themselves together with an additional drainage area to form the accumulated catchment $e$ which drains at outlet-5. Note that the sub catchment $a, b$ and $d$ are categorised as individual accumulated catchments with no upstream catchments contributing to them.

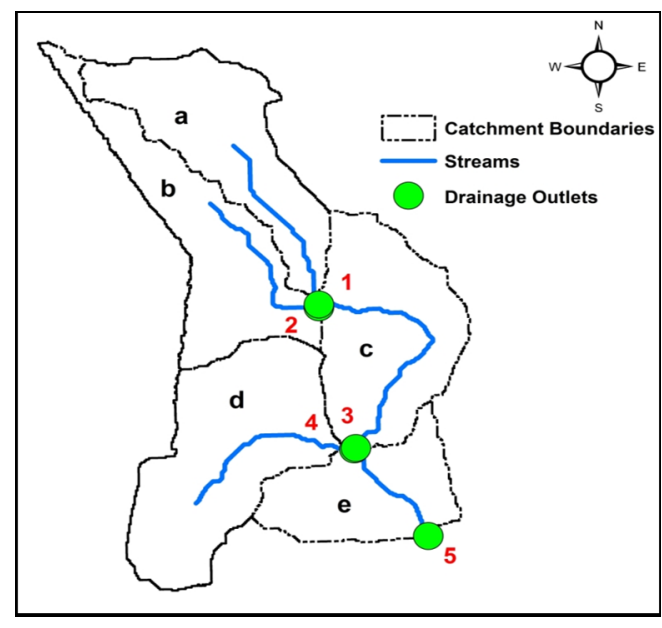

Figure 3. Accumulated Catchments

From stormwater harvesting perspective, it is essential to understand the behaviour of the catchment with respect to stormwater flows and respective water demands. The accumulated catchment terminology is immensely significant, as the decision maker has the choice of implementing stormwater harvesting schemes in various accumulated catchments depending on the amount of runoff and the nature of demand, which tend to vary in these catchments. Therefore, this study assesses runoff and demand through accumulated catchments. The drainage outlets of these catchments can be considered as potential stormwater harvesting sites where stormwater can be captured and infrastructure can be built.

Step (b) requires extensive data such as rainfall, water demands, impervious-pervious area information, Digital Elevation Model (DEM), etc. from different sources. Spatial maps can be generated for runoff and demand. For GIS based screening tool, an annual time scale of estimating runoff can be chosen for both stormwater runoff and demand, as the tool deals with preliminary evaluation and ranking of potential stormwater harvesting sites. Among various methods available to estimate runoff, the simple version of the rational method as suggested by Schueler (1987) can be used to generate the runoff map. In the GIS framework of the study, it uses a yearly 
rainfall map, a runoff coefficient map, and an impervious-pervious area map to compute yearly runoff. Runoff layer can be developed in raster format as spatial analyst tools can provide flexibility of interpolation and calculation. Similarly, the park demands can be represented spatially in GIS as demand per unit of park landuse. The present methodology uses point data of annual demands for the parks. These demands can be aggregated over respective park landuse polygons to represent the demand map per park land use. The Arc Hydro provides an elegant capability of tracing and storing aggregated upstream catchment area within considered total catchment (David 2002). By using this capability, the accumulated catchment layer in vector format can be generated from raster DEM.

In step (c), spatial maps of runoff and park demand are overlayed on the accumulated catchments. Thus, each of the drainage outlets of these accumulated catchments have attributes of runoff and demand. The ratio of the available runoff to demand for all drainage outlets (i.e. potential stormwater harvesting sites) can be computed and considered as the suitability indicator for screening. Based on this indicator, stormwater harvesting sites can be compared and ranked. The sites with high ratios can be considered as suitable stormwater harvesting sites. The suitability index of runoff to demand ratio has been considered in this study only to demonstrate the proposed methodology at this initial level of screening. However, the study plans to improve this index or to bring in additional indices, in the future.

\section{CASE STUDY}

\subsection{Data Acquisition and processing}

The required data for the study were collected from different Australian institutions and research organizations. The raw datasets included impervious area map, landuse map, study area boundaries, council boundaries, customer demand map, and DEM. Table 1 shows some details of these datasets. All raw datasets were processed into the runoff layer, the demand layer and the accumulated catchment layer using Arc GIS version 9.3, Spatial Analyst tools and Arc Hydro tools.

Table 1: Data Description

\begin{tabular}{|l|l|l|l|}
\hline Data & Source & Format & Scale \\
\hline Rainfall data & SILO & Text & $1: 300,000$ \\
\hline Impervious Area Map & Melbourne water & Vector (Polygons) & $1: 50,000$ \\
\hline Customer Demands & CWW & Vector (Point) & $1: 50,000$ \\
\hline Study Area & CWW & Vector (Polygon) & $1: 300,000(\mathrm{CWW})$ \\
& & & $1: 50,000(\mathrm{MCC})$ \\
\hline Planning Zone Map (Landuse) & CWW & Vector (Polygon) & $1: 50,000$ \\
\hline DEM (10M) & Land Victoria & Raster (ESRI Grid) & $1: 60,000$ \\
\hline
\end{tabular}

\subsection{Runoff and demand GIS layers}

The drought period of 1997-2009 was considered in developing the runoff layer as this period provides a conservative estimate for runoff in the assessment of potential stormwater harvesting opportunities. The runoff layer was generated in raster grid format of cell size $30 \mathrm{~m} \mathrm{X} \mathrm{30m.} \mathrm{The} \mathrm{selected} \mathrm{fine} \mathrm{resolution} \mathrm{was} \mathrm{based} \mathrm{on}$ trade-off consideration between spatial scale of rainfall and impervious-pervious area (parcels) map. At low (larger cell size) resolution, the information of pervious-impervious areas may be lost. Although, rainfall may not vary significantly in the $30 \mathrm{~m}$ grid, this resolution was assumed to account the minimum parcel size of 900 $\mathrm{m}^{2}$ for both pervious area and impervious area, so that information on pervious-impervious areas is not lost.

An interpolated rainfall map was prepared using SILO data of 0.05 degree $(5 \mathrm{~km})$ resolution within the CWW service area. Data were represented in GIS in terms of points. Rainfall represented by the each of SILO points was the average annual rainfall for the period of 1997-2009. Interpolation of these points was undertaken using the Inverse Distance Weighting (IDW) method through the spatial analysis tools in Arc GIS 9.3 at $30 \mathrm{~m} \mathrm{X} \mathrm{30m}$ resolution. The rainfall map was clipped for the MCC region for analysis purposes. The interpolated rainfall map for the MCC region had a range of annual average rainfall values between $497 \mathrm{~mm}$ to $537 \mathrm{~mm}$. The impervious-pervious area map consisted of information on effective impervious areas of roads, land parcels and roofs, and information on pervious areas of parks, reserves and water bodies. The same map was used to generate the runoff coefficient map where values 0.9 and 0.1 were used as runoff coefficients for impervious areas and pervious areas respectively (Argue et al. 2009). The runoff coefficient map and the imperviouspervious map were combined with the rainfall map using the 'Raster Calculator' to compute the annual runoff 
layer. The nature of the runoff values was influenced by spatial distribution of impervious areas and pervious areas, generating high and low runoff accordingly.

The City of Melbourne has high demand for potable water that is used for irrigation of various parks, golf courses, ovals, and council reserves. This potable water demand can be supplied by harvested stormwater. The park demand was represented in GIS as a layer with the attributes of demand per unit of park landuse. CWW provided the data of park customer groups representing demands of individual customers with their spatial location in shape file format (point). The annual demand data for the year 2010 was used in the analysis, as they were the most recent demands available at the time of the study. These annual demands of parks were in the range of $1 \mathrm{ML}$ to $155 \mathrm{ML}$ with $70 \%$ less than $10 \mathrm{ML}$. The park landuse was extracted from the planning zone map provided by CWW. The demand points were intersected with park landuse map to identify the demand points within existing park land use polygons of MCC. The annual demand values of the points within the park landuse polygons were summed together to represent total demand of a given park landuse area. Thus, the demand layer represented the park areas with their respective volumetric demand for the year 2010. Scope of demand layer however can be extended to any year and also to account for other types of the demands.

\subsection{GIS layers for accumulated catchments}

Using Arc Hydro tools, the DEM of $10 \mathrm{~m}$ resolution was processed to delineate the catchments in the study area. The accumulated catchment layer was then generated using 'Accumulate Shape' function of Arc Hydro resulting in 88 accumulated catchments. Catchments with area less than 10 ha were assumed unsuitable for stormwater harvesting and were not considered in the analysis.

The raster runoff layer was overlayed and aggregated over the accumulated catchment layer to compute the mean catchments runoff within the each of 88 accumulated catchments. The total volume of mean annual runoff generated by all catchments was $6.5 \mathrm{GL}$ for the study area. This value of mean runoff was compared with a study carried out by Melbourne City Council (MCC) in 2008 which indicated that mean runoff from MCC was around $13 \mathrm{GL}$ in a base year 2000 from an area of $36 \mathrm{~km}^{2}$. The $6.5 \mathrm{GL}$ figure represents mean runoff from the portion of MCC within CWW boundary of an area of $26 \mathrm{~km}^{2}$ in drought period of 1997-2009. Furthermore, mean rainfall in year $2000(629 \mathrm{~mm})$ was above the mean rainfall over the period 1997-2009 (514 mm) within MCC. Therefore, 6.5GL runoff value seems reasonable for the study area.

Similarly, demand attributes of parks were incorporated within the accumulated catchments by overlaying these values with open space landuse layer. The demands of the accumulated catchments ranged from $2 \mathrm{ML}$ to 185 ML with a mean value of 51ML. The total water demand for the study area was $1.3 \mathrm{GL}$. The catchments with no park landuse polygons overlapping were considered as accumulated catchments with no demand.

\subsection{Ranking of stormwater harvesting sites}

Table 2: Top 11 High Ratio Catchments

The ratio of runoff to demand was computed for all 88 accumulated catchments and considered in this study as the suitability index. Among 88 catchments, 25 catchments had their runoff to demand ratio greater than 5 . The accumulated catchments with no park demand were excluded from further analysis. The study generated 32 such catchments. Thus, the drainage outlets for high ratio catchments were identified as suitable sites for stormwater harvesting where stormwater infrastructure can be developed. Table 2 shows the top 11 accumulated catchments with their highest ratios of runoff to demand greater than 15. The presence of high impervious area was responsible for high yielding of runoff from the catchments. However, the ratios were varied according to the demands covered by the corresponding accumulated catchments. Park demand was highest for catchment ID-68, thereby reducing the ratio although the catchment had the highest runoff. Conversely, the catchment ID-29 had a comparatively small demand for its large runoff, therefore yielding the highest ratio.

Figure 4 represents the spatial distribution of stormwater harvesting sites based on their ratios of runoff to demand. The top 3 high ratio catchments (viz. 29, 17, and 43) are highlighted in red. The circles represent the 
drainage outlets of accumulated catchments, which are also the potential stormwater harvesting sites. The size of the circle shows the magnitude of these ratios. High ratios $(>30)$ are highlighted in blue, while moderately high ratios $(>20)$ are represented in yellow. The medium range of ratios $(>7-20)$ is symbolized in green circles. The moderately low range of ratios $(>2-7)$ is shown in purple, along with low ratio range $(<2)$ in red circles.

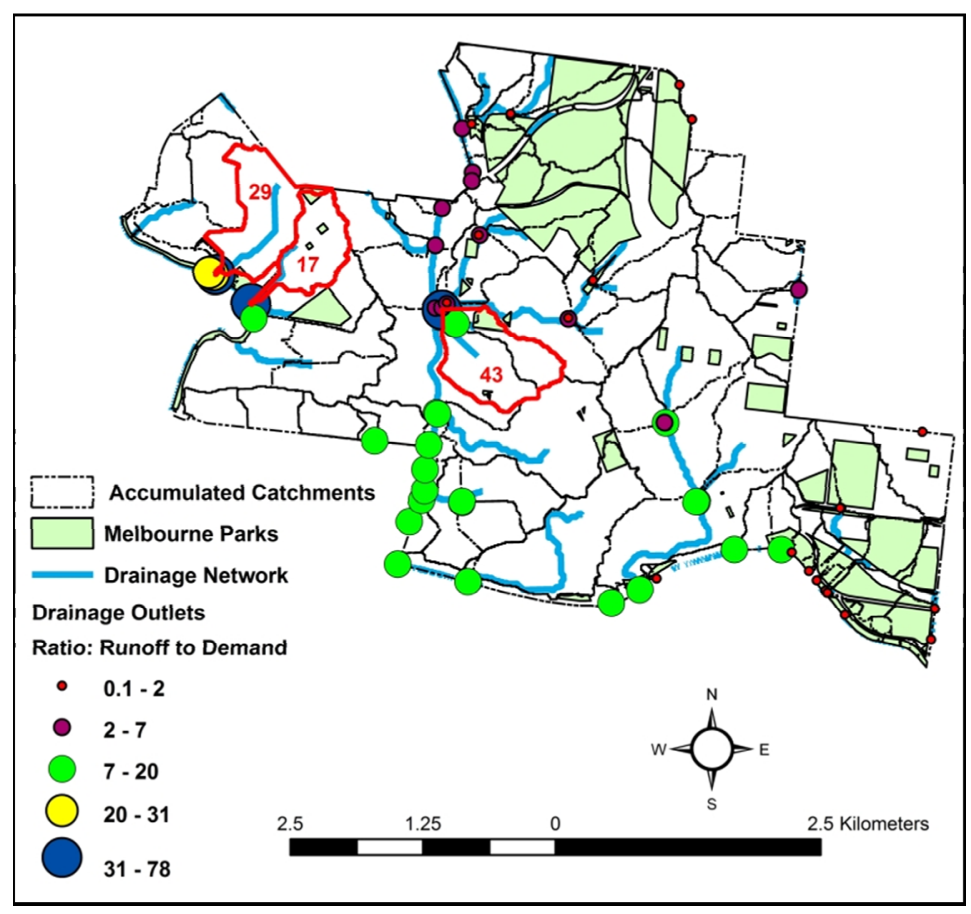

Figure 4. Spatial Distribution of Stormwater Harvesting Sites

\section{DISCUSSION}

The GIS screening tool described in this paper can identify potential suitable stormwater harvesting sites based on the concept of accumulated catchments. These sites can be ranked on the basis of ratio of runoff to demand using data of an annual scale. Suitability based on the ratios alone may not have provided the precise level of suitability assessment for stormwater harvesting catchments as the size of demands and runoff may also influence the suitability. However, the methodology can assist the decision makers at the initial level of a screening process where evaluation and ranking potential stormwater harvesting catchments can be done.

Runoff and irrigation demands from parks often tend to fluctuate seasonally. This seasonal variation was not accounted in this study. Annual scale for runoff and demand was selected only to demonstrate the application of the methodology. Besides annual demands of year 2010, maximum or mean demands for a given time period may provide different values of the suitability index. Also, with the proposed methodology, other nonresidential demands such as commercial, industrial, or institutional demands (hospital, councils, etc.) can also be mapped and suitability index can be estimated.

It will be interesting to explore the relationship between stormwater harvesting site locations and their distance to the parks. The site locations within the parks or adjacent to the parks can be then identified. Such sites may need less cost of setting infrastructure to supply the demands of the parks. The study plans to address these issues in next phase of research.

\section{CONCLUSION}

Over the recent years, stormwater harvesting has been emerging as a sustainable alternative water resource to cope with growing urban water demands. The selection of suitable stormwater harvesting sites is essential and equally challenging for the urban water infrastructure planner. The present research was focussed on developing a robust methodology for evaluating and ranking suitable stormwater harvesting sites using GIS. The methodology was successfully applied to a portion of Melbourne City Council. A concept based on accumulated catchments was introduced through which variation in runoff and demand at different catchment levels of the case study area was assessed. The suitability of these catchments for stormwater harvesting was then assessed by comparing their ratios of potential runoff to water demands. The catchments with high ratios were prioritized 
where potential stormwater harvesting schemes can be built. Thus, the methodology proposed in this study will directly benefit water authorities such as CWW at the preliminary level of stormwater harvesting scheme assessment. This Study further aims to develop detail conceptual designs for identified suitable sites from the GIS based screening tool. These sites will be evaluated with respect to social, environmental and economic perspectives in future.

\section{ACKNOWLEDGEMENT}

The authors are highly thankful to Melbourne Water and Land Victoria for the provision of the necessary data for the study.

\section{REFERENCES}

Argue, J.R., Allen, M.D., Stormwater Industry Association, Urban Water Resources Centre, UoSA and Australian Water Association (2009). Water Sensitive Urban Design: Basic Procedures for'source Control'of Stormwater: a Handbook for Australian Practice, pp. 350. University of South Australia, Adelaide, Australia.

City of Melbourne (2008), Total watermark: City as a catchment, pp. 71, http://www.melbourne.vic.gov.au/Environment/WhatCouncilisDoing/Documents/city as_catchment.p df

David, R.M. (2002). Arc Hydro: GIS for water resources, pp. 203. ESRI Press, Redlands, California, USA.

De Winnaar, G., Jewitt, G.P.W. and Horan, M (2007). A GIS-based approach for identifying potential runoff harvesting sites in the Thukela River basin, South Africa, Physics and Chemistry of the Earth, Parts $A / B / C, 32(15-18), 1058-67$.

El-Awar, F., Makke, M., Zurayk, R. and Mohtar, R. (2000). A hydro-spatial hierarchical method for siting water harvesting reservoirs in dry areas, Applied Engineering in Agriculture, 16(4), 395-404.

Fletcher, T., Deletic, A., Mitchell, V. and Hatt, B. (2008). Reuse of urban runoff in Australia: a review of recent advances and remaining challenges, Journal of Environmental Quality, 37(5 ), 116-27.

Goonrey, C.M., Perera, B.J.C., Lechte, P., Maheepala, S. and Mitchell, V.G. (2009). A technical decisionmaking framework: stormwater as an alternative supply source, Urban Water Journal, 6(6), 417 - 29.

Hatt, B.E., Deletic, A. and Fletcher, T.D. (2006). Integrated treatment and recycling of stormwater: a review of Australian practice, Journal of Environmental Management, 79(1), 102-13.

Kahinda, J., Lillie, E., Taigbenu, A., Taute, M. and Boroto, R. (2008). Developing suitability maps for rainwater harvesting in South Africa, Physics and Chemistry of the Earth, 33(8-13), 788-99.

Kumar, M., Agarwal, A. and Bali, R. (2008). Delineation of potential sites for water harvesting structures using remote sensing and GIS, Journal of the Indian Society of Remote Sensing, 36(4), 323-34.

Malczewski, J. (2004). GIS-based land-use suitability analysis: a critical overview, Progress in Planning, 62(1), 3-65.

Mbilinyi, B., Tumbo, S., Mahoo, H., Senkondo, E. and Hatibu, N. (2005). Indigenous knowledge as decision support tool in rainwater harvesting, Physics and Chemistry of the Earth, 30(11-16), 792-8.

Mbilinyi, B.P., Tumbo, S.D., Mahoo, H.F. and Mkiramwinyi, F.O. (2007). GIS-based decision support system for identifying potential sites for rainwater harvesting, Physics and Chemistry of the Earth, Parts $A / B / C, 32(15-18), 1074-81$.

Mitchell, G., Mein, R. and McMahon, T. (2002). Utilising stormwater and wastewater resources in urban areas, Australian Journal of Water Resources, 6(1), 31-43.

Mitchell, V., Taylor, A., Fletcher, T. and Deletic, A. (2005). Storm water reuse-Potable water substitution for Melbourne, ISWR Rep.

Mitchell, V., Deletic, A., Fletcher, T., Hatt, B. and McCarthy, D. (2007). Achieving multiple benefits from stormwater harvesting, Water Science and Technology, 55(4), 135-44.

Schueler, T.R. (1987).Controlling urban runoff: a practical manual for planning and designing urban BMPs, prepared for Washington Metropolitan Water Resources Planning Board, Washington, D.C.

Shipton, M.D. and Somenahalli, S.V.C. (2010). Locating, appraising, and optimizing urban storm water $\begin{array}{lllll}\text { harvesting } & \text { sites, } & \text { viewed } & 12 & \text { February }\end{array}$ $<$ http://www.esri.com/news/arcnews/spring10articles/locating-appraising.html $>$.

Singh, J., Singh, D. and Litoria, P. (2009). Selection of suitable sites for water harvesting structures in Soankhad watershed, Punjab using remote sensing and geographical information system (RS\&GIS) approach-A case study, Journal of the Indian Society of Remote Sensing, 37(1), 21-35. 